\title{
Penta-Band Dielectric Loaded Folded Loop Antenna for Mobile Handset
}

\author{
Mustafa Abu Nasr ${ }^{1}$, Fady I. El-Nahal ${ }^{2}$, A. Mohamed Alutol ${ }^{3}$ \\ ${ }^{1}$ Engineering Department, Faculty of Engineering and Information Technology, Al-Azhar University, Gaza, \\ Palestine. \\ ${ }^{2,3}$ Electrical Engineering Department, Faculty of Engineering, Islamic University of Gaza, Gaza, Palestine.
}

\begin{abstract}
A compact internal penta-band folded loop antenna for LTE1600/2600/WIMAX3.5/WLAN2.4/5.2 multiple mobile operations is proposed and investigated. The whole antenna structure is formed of a single folded meander loop pattern mount on the surfaces of a dielectric carrier with L-shape have a volume of 20 $\mathrm{mm} \times 17 \mathrm{~mm} \times 5 \mathrm{~mm}$, and ground plane of length $110 \mathrm{~mm}$ is used. The size of the total structure is $110 \times 50 \times$ $5 \mathrm{~mm}^{3}$. The compact structure makes it very suitable for today's mobile phones applications. With $6 \mathrm{~dB}$ return loss, five operating frequency bands covering LTE/WLAN/WiMAX MHz can be achieved with our design. Also, the resonant characteristics of the antenna can be tuned by using various strip dimensions and also the dielectric material of the carrier. Moreover, simulated results exhibit that the proposed folded loop antenna features nearly good omnidirectional radiation patterns with proper gain. The design and optimizing of the performance of the proposed antenna are performed by using a high frequency structure simulator HFSS. Details of the various antenna parameters are presented and discussed in this paper.
\end{abstract}

\section{INTRODUCTION}

With the rapid evolution of wireless communication technologies, and the changing nature of consumer needs for mobile devices, mobile handsets have been gradually rising towards miniaturized, ultra-slim, highly integrated, multi-system and high-performance. Hence the demands for designing multi-band compact antennas to meet the growing desires of integrating more applications in close proximity inside the limited space of the mobile handsets are increased continuously. In order to meet theses modern needs, a range of novel mobile handsets antennas have been designed. Planar inverted-F antennas (PIFA) and inverted-F antennas (IFA) are popular in most handsets for mobile phone applications, this is basically due to their small size, easy fabrication, and low manufacturing cost [1],[2]. As the mobile handset device is quite small, the characteristics of PIFA and IFA depends on the ground plane of the antenna as it used as part of the radiator thereby improve the bandwidth and gain performance,[3],[4]. However, the current variation due to the device being handheld and the resulting body proximity impact reduce antenna performance since the resonating currents are spread out over the system ground plane [5], [6]. It has been shown that a folded loop antenna can decrease the currents on the ground plane significantly at the same time maintaining a good performance [7], [8]. Loop antennas are characterized by closed current paths build on radiating elements, which comply with a variety of closed planar geometries. Loop antennas can be employed by directly printing on the mobile's phone board [9], or printing on a dielectric carrier and then mounted above the system circuit board [10],or it can be can be also configured to be attached as a chip antenna as a surface-mountable on the system circuit board [11]. These all make loop antenna very attractive for the publishers and applications of new mobile phone antenna projects. However, unlike the conventional mobile phone antennas such as (PIFAs) operated as quarter-wavelength resonant structures [12], the first resonant mode of the reported multiband loop antennas for mobile phone applications is a halfwavelength resonant mode. This makes it a challenge for reaching a compact volume for the loop antenna to be inserted inside the mobile phone as an internal antenna.

In this paper, a penta-band dielectric loaded folded loop antenna for practical application is proposed. The proposed antenna can deliver wide operating bandwidths covering LTE1600/ 2500, WiMAX 3500, WLAN 2.4/5.2, and WLAN 5.8 band. The proposed loop antenna comprises a folded uniform loop strip attached on a dielectric carrier. Simply by adjusting proper dimensions of parts of stripes, good excitation can be obtained. The simulated antenna's reflection coefficient and radiation efficiency are proved that the proposed antenna works as expected and agree with the required band of practical applications. Details of the design of the antenna are described in Section II, Parametric study for the antenna will be performed and discussed in Section III. Results are explained in part IV, Finally, this paper will be concluded with a brief summary in Section V.

\section{ANTENNA DESIGN}

The antenna have been designed for a typical hand held device such as Smartphone. While designing the antenna the form factor of a practical Smartphone of $110 \mathrm{~mm}$ x $50 \mathrm{~mm}$ was considered. The overall geometry 
of the proposed antenna is illustrated in Figs. 1 (a-c). The antenna consists of a closed loop metal structure folded pattern mounted on an L-shape dielectric carrier which is placed at the top of PCB board. The board have a thickness of $0.8 \mathrm{~mm}$ and an area of $110 \mathrm{~mm} \times 50 \mathrm{~mm}$ is made of FR4-Epoxy material with a relative permittivity of 4.4 and a loss tangent of 0.02 . The carrier made of material of relative permittivity of 3 and a height of $(\mathrm{h}=5 \mathrm{~mm})$ from ground plane. A $50 \Omega$ lumped port is used to excite the loop antenna pattern on the front side of the main board connected to the feeding point of the loop, while the other end is connected to the ground plane at the shorting point. The dimensions of the folded loop antenna and the ground plane in an unfolded form are detailed in Fig. 2 (c). The folded loop antenna track have a width of $1 \mathrm{~mm}$ in most parts except that the section (L1), and section (L2) are $2 \mathrm{~mm}$ width. The detailed optimized dimensions of the proposed folded loop antenna metal pattern model are given in table 1.

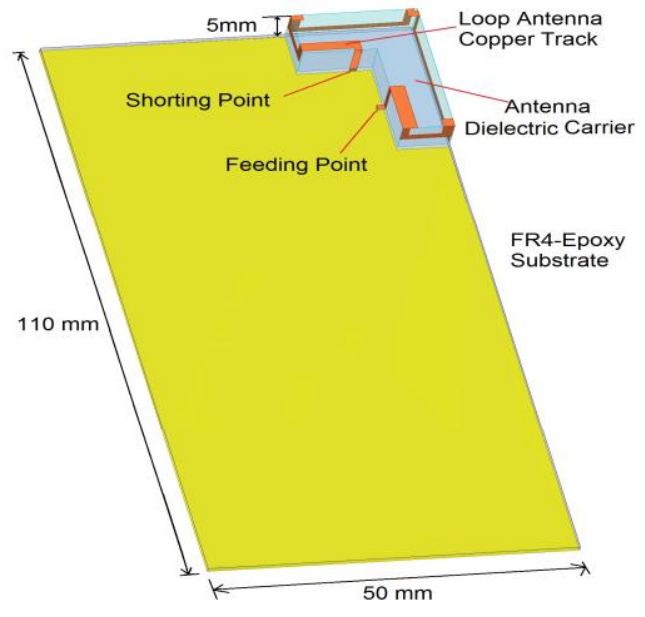

(a)

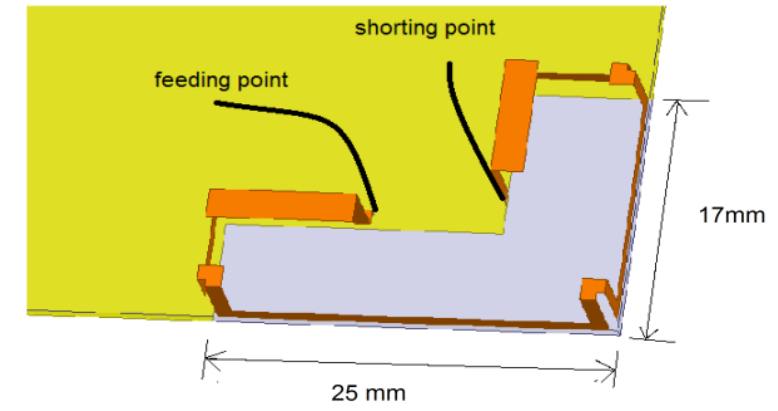

(b)

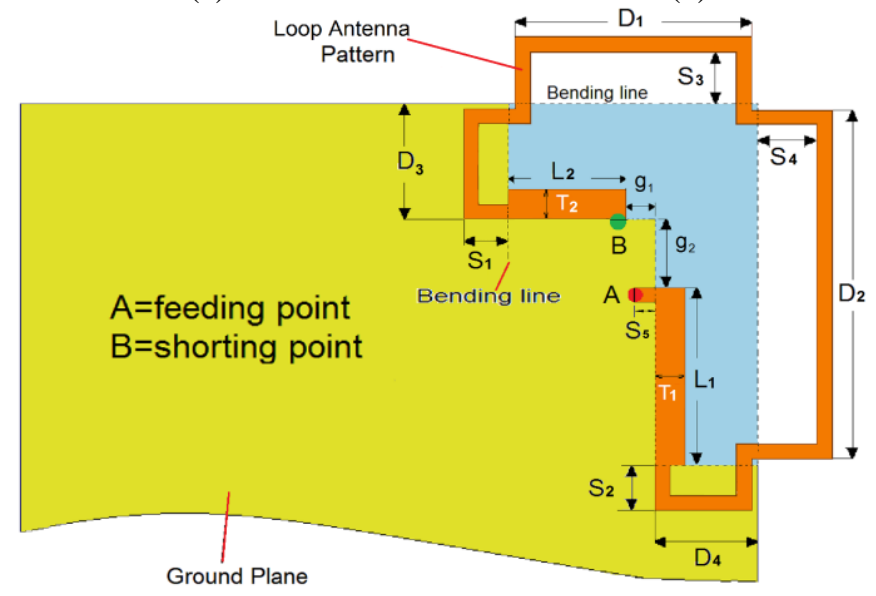

(c)

Fig. 1 (a) Antenna geometry of the proposed folded loop antenna (b) Antenna without carrier (c) Detailed dimensions of the antenna unfolded into a planar structure.

TABLE 1: Table 1 Detailed dimensions of the proposed antenna

\begin{tabular}{|c|c|c|c|c|c|c|}
\hline \multicolumn{7}{|c|}{ Unites :mm } \\
\hline D1 & D2 & D3 & D4 & L1 & L2 & g1 \\
\hline 16 & 24 & 8 & 7 & 9 & 8 & 2 \\
\hline S1 & S2 & S3 & S4 & S5 & T1 & g2 \\
\hline 3 & 3 & 3.5 & 4 & 2 & 2 & 8 \\
\hline
\end{tabular}

\section{PARAMETRIC STUDY}

In this section, we investigate the impact of varying antenna parameters on its performance and frequency response. All parametric study results presented considered varying one parameter at a time and the other parameters are fixed to a certain value, whereas the best value obtained from the individual parametric study results. The antenna component values and the antenna structure were first modeled with variables. Then, 
HFSS [13] have been set to run simulations for number of different values of the variables, the main purpose is to find a better performance of the folded loop antenna to cover the required LTE band.

\section{A. Effects of the upper stripe length L1}

Fig. 2 shows the effect of changing the length L1 on the antenna S-Parameters (S11) performance. Four values, $8,9,10,11$ ) of length of L1 have been chosen to monitor the changes in the antenna performance, other values are set to a certain values. We notice that as the length of L1 stripe increases the resonant frequencies will shift to the left in the graph, which mean that the resonant frequency of the antenna will decreased. A length L1 variations have the effect on the high resonances frequency bandwidth more than the value of return loss.

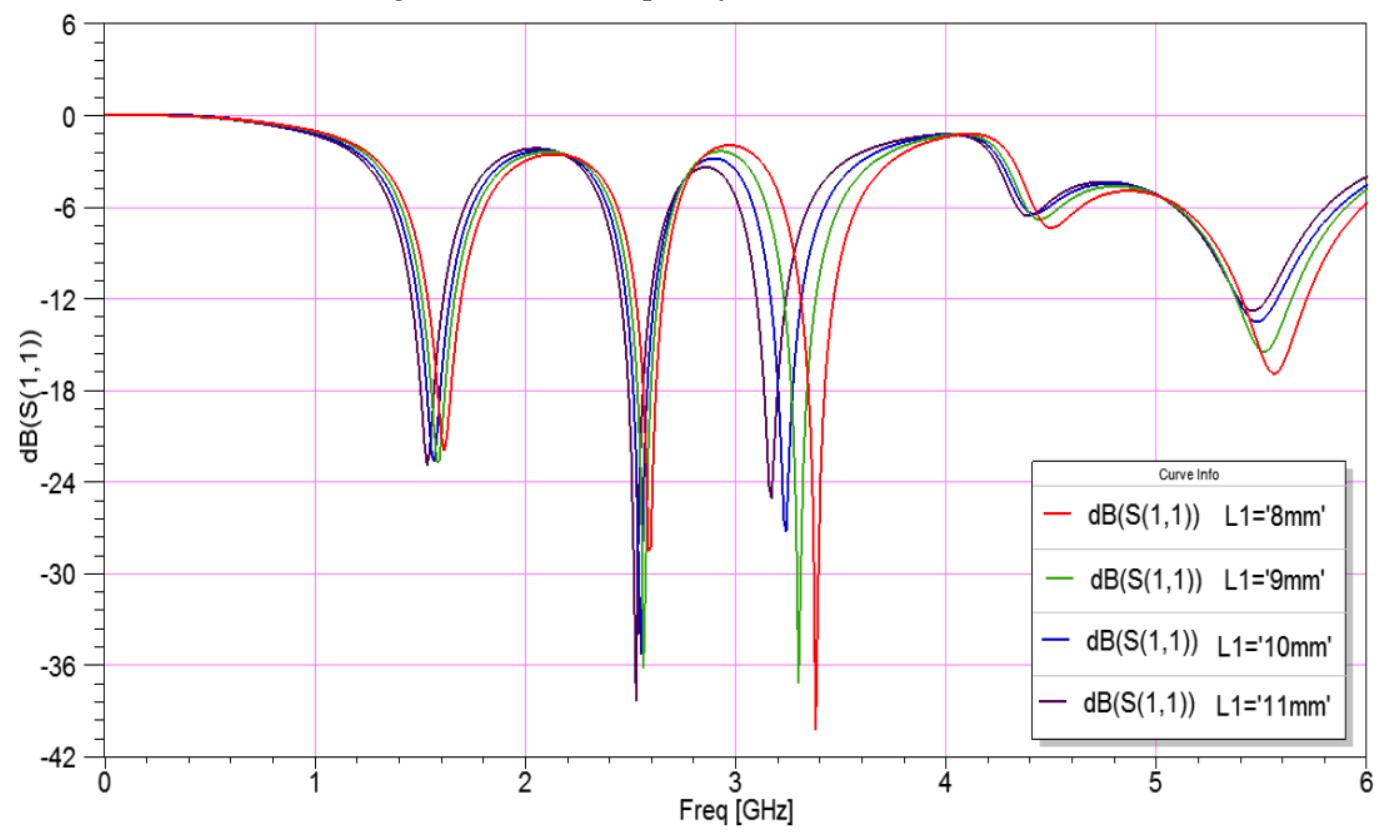

Fig. 2 Simulated results as a function of length L1 (Upper stripe length).

\section{B. Effects of the lower stripe length $\mathrm{L2}$}

The variation in L2 also affect the antenna resonances. Fig. 3 shows that the length of the L2 shift the S-Parameter curve to the right. A length L2 have the effect on antenna return loss values and bandwidth less than the effect of L1,

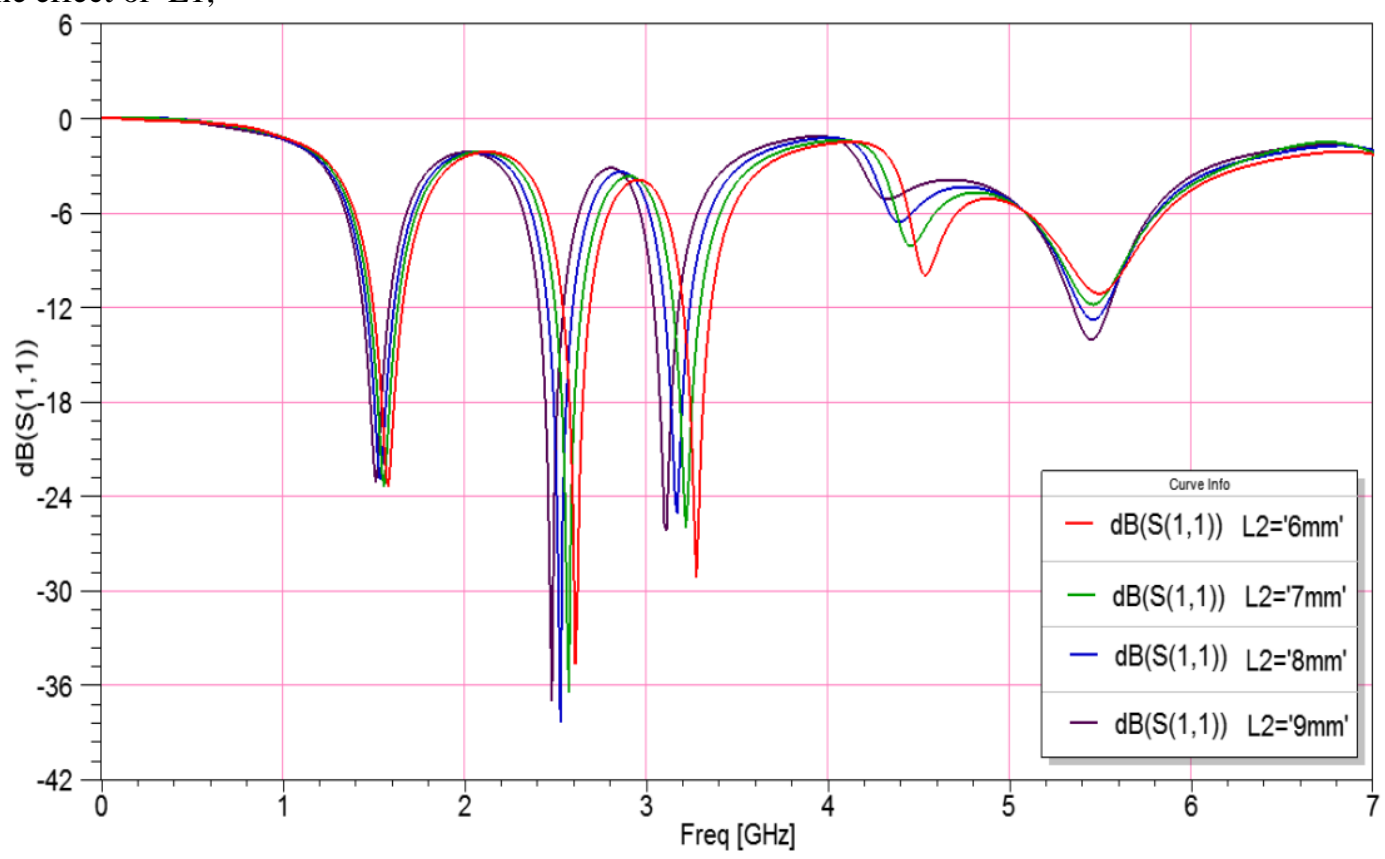

Fig. 3 Simulated results as a function of length L2 (Lower stripe length). 


\section{Effects of dielectric relative permittivity $\varepsilon_{\mathrm{r}}$}

Antennas can be loaded by a dielectric material, the shape and permittivity of the material determines the effective wavelength. As the wavelength is shorter in a high permittivity material, the effective wavelength of an electromagnetic wave is shorter than that in free space. This is due to the concentration of the electric field in high permittivity materials, therefore, the antenna size can be reduced and hence the folded loop antenna can be made smaller in size. Apart from size reduction, another reason to use dielectric material is that they are more resistant to detuning when placed to other objects like the human body in the case of the handset antennas. If the dielectric material is used in the antenna where the electric fields or currents are high, it makes the antenna more efficient than its all metal counterpart. The impact of the dielectric loading on the antenna resonance have been evaluated using (HFSS), four values of relative permittivity $\varepsilon_{\mathrm{r}}$ values ranging from 2 to 5 with 1 steps were used to investigate the change in the antenna return loss, As shown in Fig. 4 , variations in $\left(\varepsilon_{\mathrm{r}}\right)$ have a significant impact on the antenna operating band. We observe that as we increase the relative permittivity of the dielectric material the resonance frequency will shift to left and the return loss magnitude will increased.

\section{A. Return Loss}

\section{RESULTS ANALYSIS}

Fig. 5 illustrates the simulated impedance bandwidth of the optimized proposed loop antenna. The graph shows the return loss as a function of frequency $\mathrm{f}$ which sweeps from $1 \mathrm{GHz}$ to $7 \mathrm{GHz}$. As seen, five impedance bandwidths for the proposed antenna have been determined, the bandwidth for these bands has been determined according to the reflection coefficient (S11) level of $-6 \mathrm{~dB}$.

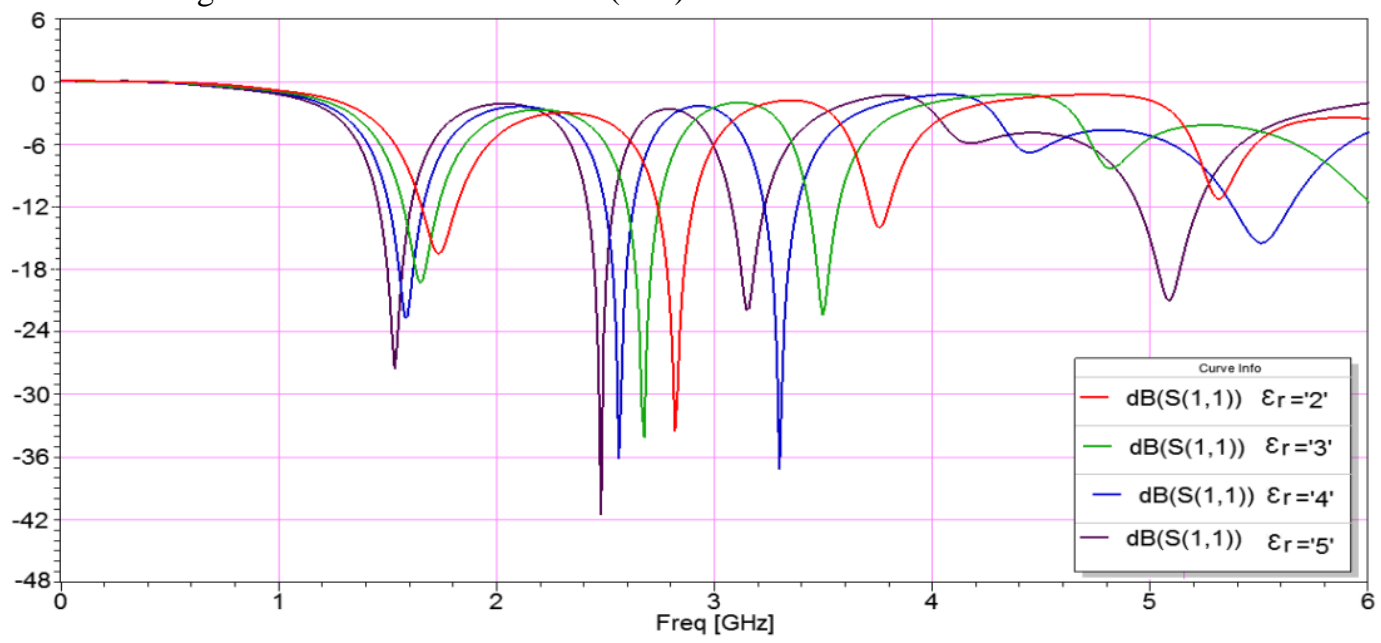

Fig. 4 Simulated results as a function of dielectric relative permittivity \&r

These bands are marked as band \#1 $(1.4 \mathrm{GHz}-1.77 \mathrm{GHz})$, band \#2 (2.4 GHz $-2.7 \mathrm{GHz})$, band \#3 $(3.14 \mathrm{GHz}-3.5 \mathrm{GHz})$, band \#4 $(4.3 \mathrm{GHz}-4.53 \mathrm{GHz})$ and band $\# 5(5.1 \mathrm{GHz}-5.9 \mathrm{GHz})$. It noticed that as the frequency increases, the operating frequency modes have wider bandwidth. In band 1, the best S11 is of $-21 \mathrm{~dB}$, band 2 at $-30 \mathrm{~dB}$, band 3 at $-31 \mathrm{~dB}$, band 4 at $-8 \mathrm{~dB}$, and band 5 at $-16 \mathrm{~dB}$.

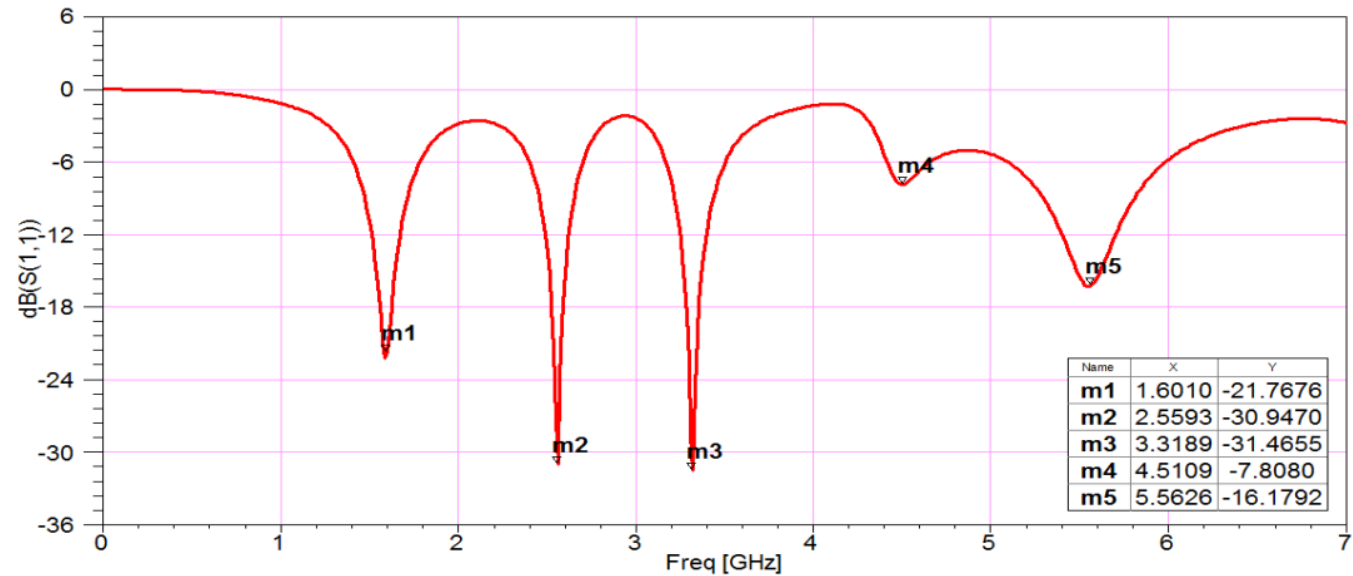

Fig. 5 Simulated return loss Vs Frequency. 
The simulated real and imaginary antenna input impedance plot is shown in Fig. 6, tin general the impedance matching plots agree will with the required impedance matching.

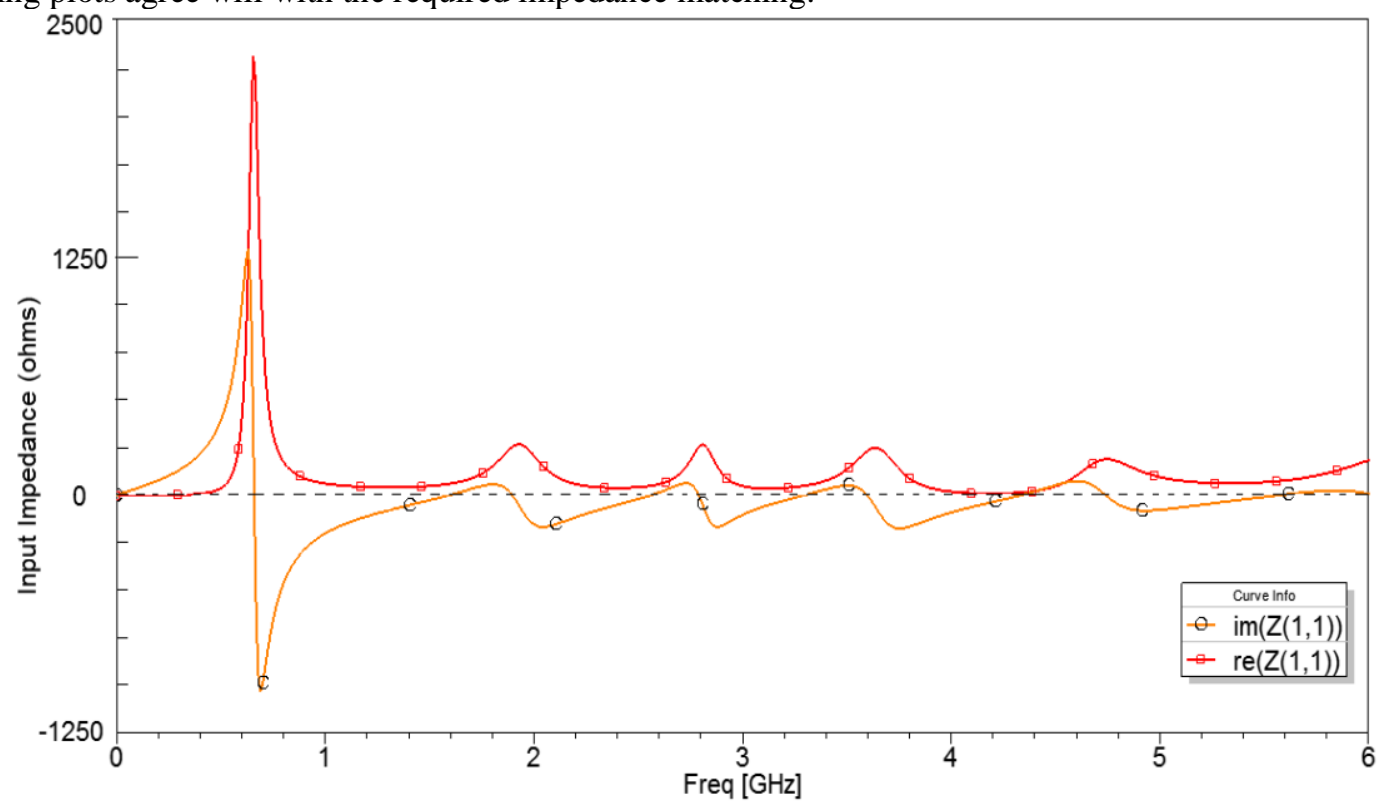

Fig. 6 real and imaginary parts of input impedance of proposed antenna.

\section{B. Current distribution}

The current distribution is plotted in Figs. 7 (a-d), the strongest current distribution is on the meandered line and it is seen that the induced current in the ground plane is negligible except very close to the antenna which prove the advantage of this balanced loop antenna, The currents at $1.6 \mathrm{GHz}$ is shown in Fig. 7 (a), $2.55 \mathrm{GHz}$ in Fig. 7 (b), $3.3 \mathrm{GHz}$ in Fig. 7 (c) and finally $5.5 \mathrm{GHz}$ is shown in Fig. 7 (d).

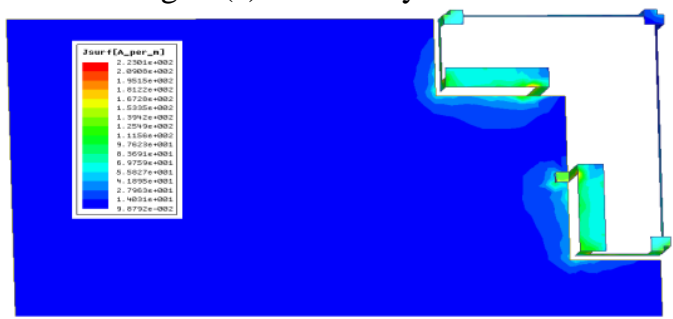

a. $1600 \mathrm{MHz}$

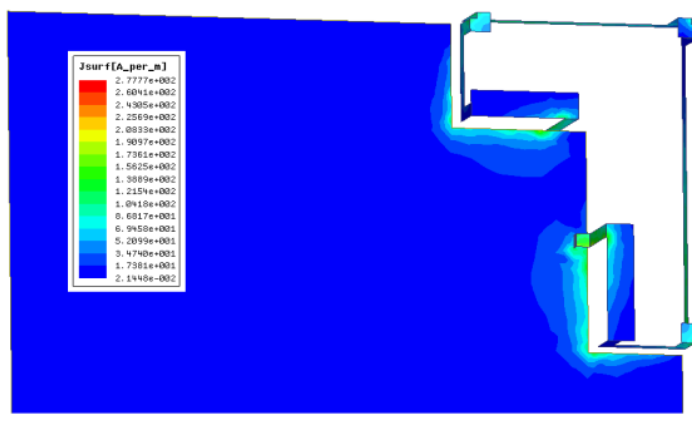

c. $3300 \mathrm{MHz}$

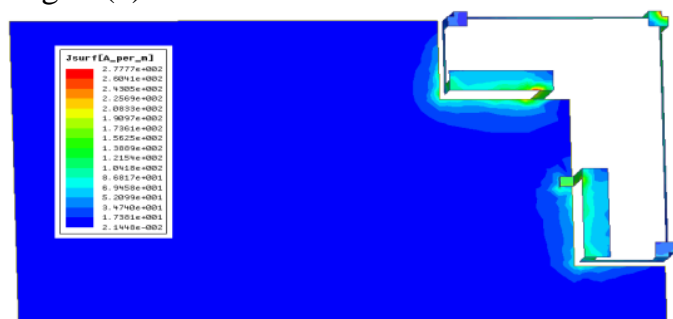

b. $2550 \mathrm{MHz}$

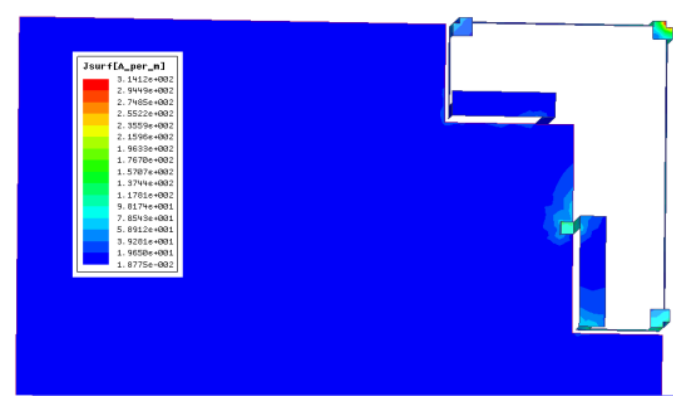

d. $5500 \mathrm{MHz}$

Fig. 7 Simulated excited surface current distributions at centre resonant frequencies of the four resonant modes for the proposed antenna with the system ground plane at $(1600,2550,3300$, and $5500 \mathrm{MHz})$

\section{Radiation Pattern}

Figs. 8 (a-d) shows the simulated 2D co-polarization and cross-polarization realized gain radiation patterns for the XZ and the YZ planes for 1.6 GHz, 2.55 GHz, 3.3 GHz and 5.5 GHz. The related 3-D radiation patterns are also shown in Figs. 8 (a-d), the radiation patterns are close to Omni-directional radiation pattern, and these features are suitable characteristics for mobile phones. Fig. 11 shows the peak gains, the simulated antenna gain over the band varied from around $0.2-3.0 \mathrm{dBi}$, so better communication quality for LTE/WLAN/WiMAX systems can be realized as well. 

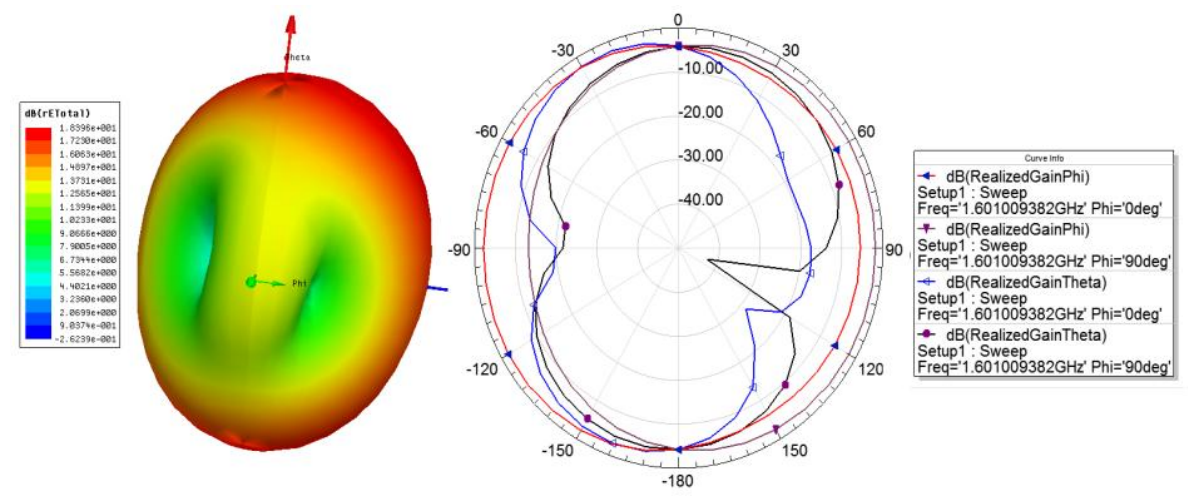

a. $1600 \mathrm{MHz}$
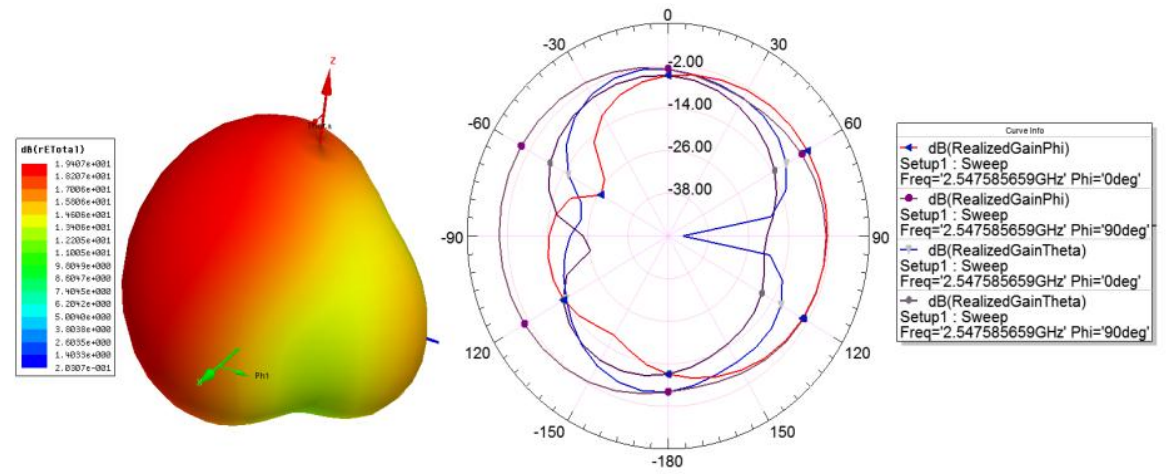

b. $2550 \mathrm{MHz}$
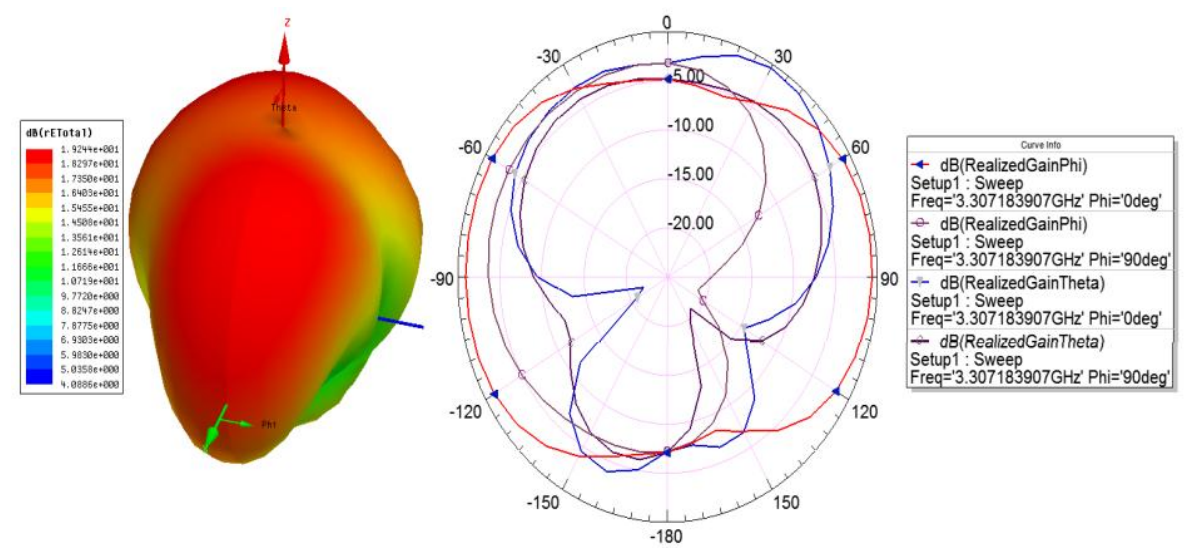

c. $3300 \mathrm{MHz}$
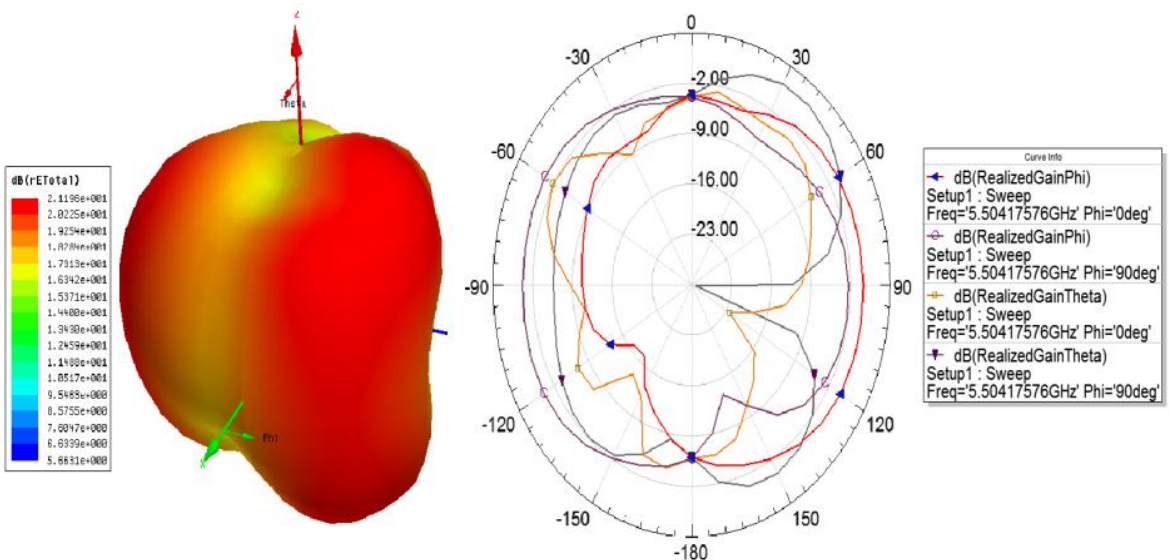

d. $5500 \mathrm{MHz}$

Fig. 8 Simulated radiation pattern at $1600 \mathrm{MHz}, 2550 \mathrm{MHz}, 3300 \mathrm{MHz}$, and $5500 \mathrm{MHz}$ respectively. 


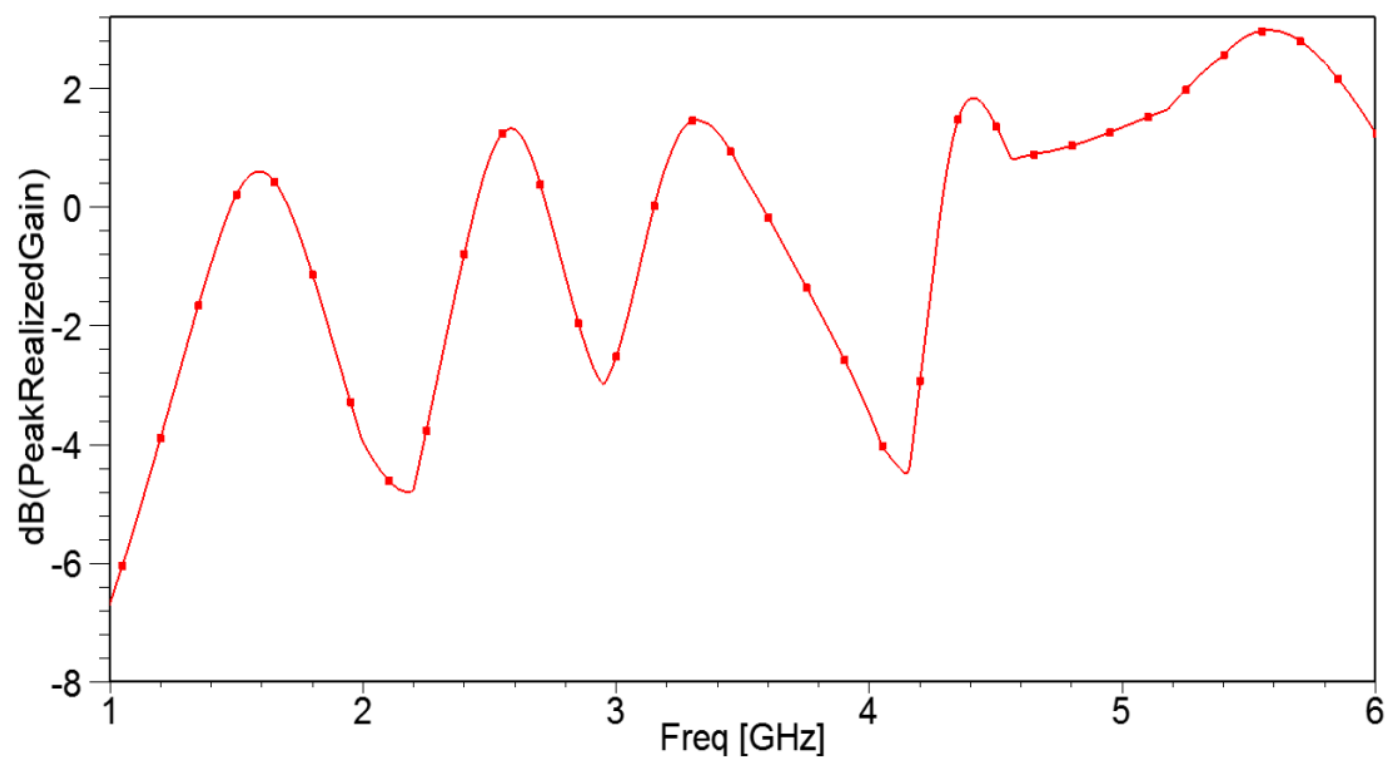

Fig. 9 Simulated peak gain of the loop antenna.

\section{CONCLUSION}

A multiband folded loop antenna designed for mobile phones has been demonstrated and studied. The proposed loop antenna generates four impedance bandwidths (1400-1770, 2400-2700, 3146-3500, and 5090$5900 \mathrm{MHz}$ ) which can be used to cover the multiple LTE/WLAN/WiMAX mobile phone operations. The antenna structure is simple, compact and flexible makes the design easy to manufacture and production. The results of the numerical software simulation are in good agreement as expected.

\section{REFERENCES}

[1] Y. J. Chi, C. W. Chiu, and S. M. Deng, "Internal quad-band printed antenna for PDA phone," Electronics Letters, Vol. 45, No. 10, 489-491, May 2009.

[2] C. W. Chiu and Y. J. Chi, "Planar hexa-band inverted-F antenna for Portable device applications," IEEE Antenna and Wireless Propagation Letters, vol. 8, pp.1099-1102, October, 2009.

[3] M. Hunynh and W. Stutzman, "Ground plane effects on planar inverted-F antenna (PIFA) performance," IEEE Proc. Microwave Antennas Propagation, vol. 150, no. 4, pp. 209-213, 2003.

[4] M. F. Abedin and M. Ali, "Modifying the ground plane and its effect on planar inverted-F antennas (PIFAs) for mobile phone handsets," IEEE Antennas Wireless Propagation. Letter, vol. 2, No. 15, pp. 226-229, 2003

[5] H. Morishita, Y. Kim, and K. Fujimoto, "Design concept of antenna for small mobile terminals and the future perspective," IEEE Transactions on Antennas and Propagation, vol. 55, No. 5, 30-43, Oct. 2002.

[6] P. Vainikainen, J. Ollikainen, O. Kivekas, and I. Kelander, "Resonator-based analysis of the combination of mobile handset antenna and chassis," IEEE Transactions on Antennas and Propagation, vol. 50, No. 10, 1433-1444, Oct. 2002.

[7] H.Morishita, Y.Kim, Y.Koyanagi, and K.Fujimoto, "A folded loop antenna system for handsets," IEEE AP-S Proc., vol. 3, pp. 440-443, Jul 2001.

[8] Y.Kim, H.Morishita, Y.Koyanagi and K.Fujimoto, "A folded loop antenna system for handsets developed and based on the advanced design concept," IEICE Trans. on Communication, vol. E84- B, no. 9, pp. 2468-2475, Sept 2001.

[9] Y. W. Chi and K. L. Wong, "Internal compact dual-band printed loop antenna for mobile phone application," IEEE Transaction Antennas Propagation, vol. 55, pp. 1457-1462, May 2007.

[10] B. Jung, H. Rhyu, Y. J. Lee, F. J. Harackiewwicz, M. J. Park, and B. Lee, "Internal folded loop antenna with tuning notches for GSM/GPS/ DCS/PCS mobile handset applications," Microwave Optical Technology. Letters, vol. 48, pp. 1501-1504, Aug. 2006.

[11] W. Y. Li and K. L. Wong, "Surface-mount loop antenna for amps/GSM/DCS/ PCS operation in the mobile phone," Microwave Opt. Technol. Letters, vol. 49, pp. 2250-2254, Sep. 2007.

[12] K. L. Wong, "Planar Antennas for Wireless Communications," New York: Wiley, 2003.

[13] ANSYS HFSS, Ansys Inc, http://www.ansys.com/Products/Simulation+Technology/Electronics/Signal + Integrity/ANSYS+HFSS/Features. 